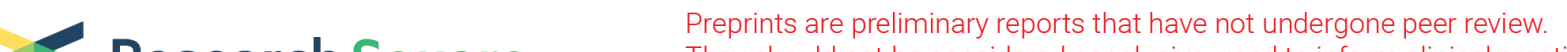 Research Square They should not be considered conclusive, used to inform clinical practice, or referenced by the media as validated information.
}

\section{Systematic evaluation of CdSe/ZnS Quantum Dots toxicity on the reproduction and offspring health in male BALB/c mice}

Li Li

Shenzhen University

Xiaotan Lin

Shenzhen People's Hospital

Tingting Chen

Shenzhen University https://orcid.org/0000-0001-5507-4590

Kan Liu

Shenzhen University

\section{Zhiwen Yang}

Shenzhen University

\section{Yajing Chen}

Shenzhen University

Dongmeng Liu

Shenzhen University

\section{Gaixia Xu}

Shenzhen University

\section{Xiaomei Wang}

Shenzhen University

\section{Guimiao Lin ( $\square$ gmlin@szu.edu.cn )}

Base for International Science and Technology Cooperation: Carson Cancer Stem Cell Vaccines R\&D Center, Shenzhen Key Lab of Synthetic Biology, Department of Physiology, School of Basic Medical Sciences, Shenzhen University

\section{Research}

Keywords: Quantum dots, reproductive toxicity, developmental toxicity, spermatogenesis, offspring health

Posted Date: June 22nd, 2020

DOI: https://doi.org/10.21203/rs.3.rs-35995/v1 
License: (c) (i) This work is licensed under a Creative Commons Attribution 4.0 International License. Read Full License

Version of Record: A version of this preprint was published at Ecotoxicology and Environmental Safety on March 1st, 2021. See the published version at https://doi.org/10.1016/j.ecoenv.2021.111946. 


\section{Abstract}

Background: Increased applications of quantum dots (QDs) in biomedical field have aroused attention for their potential toxicological effects. Although many studies have been carried out on the toxicity of QDs, their effects on reproductive and development are still unclear. In this study, we systematically evaluated the male reproductive toxicity and developmental toxicity of CdSe/ZnS QDs in BALB/c mice.

Results: The male mice were injected intravenously with CdSe/ZnS QDs at the dosage of $2.5 \mathrm{mg} / \mathrm{kg} \mathrm{BW}$ or $25 \mathrm{mg} / \mathrm{kg} \mathrm{BW}$, respectively, and the survival status, biodistribution of QDs in testes, serum sex hormone levels, histopathology, sperm motility and acrosome integrity was measured on Day 1, 7, 14, 28 and 42 after injection. On Day 35 after treatment, male mice were housed with non-exposed female mice, and then offspring number, body weight, organ index and histopathology of major organs, blood routine and biochemical tests of offspring were measured to evaluate the fertility and offspring health. The results showed that CdSe/ZnS QDs could rapidly distribute in the testis, and the fluorescence of QDs could still be detected on Day 42 post-injection. QDs had no adverse effect on the structure of testis and epididymis, but high-dose QDs could induce apoptosis of Leydig cells in testis at an early stage. No significant differences in survival of state, body weight organ index of testis and epididymis, sex hormones levels, sperm quality, sperm acrosome integrity and fertility of male mice were observed in QDs exposed groups. However, the development of offspring was obviously influenced, which was mainly manifested in the slow growth of offspring, changes of organ index of main organs, and the abnormality of liver and kidney function parameters.

Conclusion: Our findings revealed that CdSe/ZnS QDs were able to cross the blood-testis barrier (BTB), produce no discernible toxic effects on the male reproductive system, but could affect the healthy growth of future generations to some extent. In view of the broad application prospect of QDs in biomedical fields, our findings might provide insight into the biological safety evaluation of the reproductive health of QDs.

\section{Background}

Quantum dots (QDs) is a kind of semiconductor nanocrystal (2-20 nm), which has unique optical and electrical characteristics such as narrow and symmetrical emission spectrum, adjustable size and material composition [1]. It has been gradually developed into a new type of fluorescent probe, bringing changes to biological imaging and disease diagnosis [2, 3]. In recent years, the application of QDs in biological and biomedical fields has been explored, and their application range depends largely on the efficacy and toxicology [4]. However, because of the potential toxicity from heavy metals, the biosafety of QDs with heavy metals as the core, especially $\mathrm{Cd}^{2+}$ (cadmium) such as CdSe (cadmium selenide) and CdTe (cadmium telluride) has attracted great attention of the researchers $[5,6,7]$. Although many progress has been made in it, the potential toxicity of Cd-based QDs has not been fully elucidated. Therefore, it is extremely important to evaluate its toxicological properties systematically and in detail before applying it to biomedicine. 
The toxicity of QDs depends on their physical and chemical properties and environmental conditions, such as the size, charge, concentration, coating biological activity, oxidation, photolysis and mechanical stability [8]. Recently, more and more attention has been paid to the reproductive toxicity of QDs in spermatogenesis, because it has been found that QDs can cross the blood-testis barrier [9]. They caused hormone level changes, testis tissue structure damage, seminiferous tubules deformation, sperm number reduction, and ultimately led to spermatogenesis dysfunction [10]. In the male reproductive system, testis, the primary gonadal organ, especially its internal spermatocytes, are more sensitive to exogenous stimulation [11]. For instance, Qu et al. found although MPA-CdSe@ZnS QDs had no obvious toxic effect on nematodes in short term, it could lead to late toxicity such as fertilization difficulty and damage of fertilized eggshell in the long term [12]. Li et al. found that CdTe QDs could accumulate in the testis of mice after tail vein injection, reduce the sperm quality of mice and cause the change of sex hormone level, including serum testosterone $(\mathrm{T})$, luteinizing hormone $(\mathrm{LH})$ and follicle stimulating hormone (FSH) [13].

In our previous study, we evaluated the immunotoxicity of CdSe/ZnS QDs in vitro (macrophage cell line RAW264.7 and mouse spleen lymphocytes) and in vivo (BALB/c mice) [14]. Our results indicated that exposure to CdSe/ZnS QDs could disturb the function of immune cells and interfere the immune response towards external stimuli. In vivo distribution analysis showed that strong fluorescence signals from QDs could be observed in the liver and spleen of mice, and weak fluorescence signals from QDs were detected in the lung, heart, kidney and brain. It is well known that male reproductive system is more sensitive and vulnerable to various stress such as heavy metals, exogenous compounds and nanoparticles (NPs) than other organ systems $[15,16]$. However, the toxicity of CdSe/ZnS QDs to the male reproductive system and development of offspring over multiple generations is still unknown till now. Hence, in this study, we systematically investigated the male reproductive and developmental toxicity of CdSe/ZnS QDs after intravenous injection. The survival status of mice, biodistribution in testes, serum sex hormone levels, histopathology and sperm motility and acrosome integrity were observed at 1, 7, 14, 28 and 42 days after injection. The fertility and offspring development were also assessed after the QDstreated male mice were housed with non-exposed female mice. Through the systematic evaluation of the reproductive toxicity and developmental toxicity of CdSe/ZnS QDs, our research may provide further understanding of the biosafety of QDs, which is of great significance.

\section{Results And Discussion}

\section{Characterization of CdSe/ZnS QDs}

The structure, particle diameter and optical properties of CdSe/ZnS QDs used in this study were characterized and showed in Figure 1. The TEM image (Fig. 1A) indicated the CdSe/ZnS QDs were ellipsoidal in shape, with uniform morphology and no obvious aggregation. The diameter of QDs was about $(6.11 \pm 1.03) \mathrm{nm}$ (minor axis) $\times(11.01 \pm 1.77) \mathrm{nm}$ (major axis) according to the statistical results of TME image. The average hydrodynamic diameter determined by DLS was about (10.60 \pm 1.25$) \mathrm{nm}$ (Fig. 1B), and the zeta potentials were - $(22.15 \pm 2.18) \mathrm{mV}$. As shown in Fig. 1C, the first absorption peak 
of CdSe/ZnS QDs was about $650 \mathrm{~nm}$. The PL spectrum demonstrated that the emission spectrum was narrow and symmetrical, with the emission peak was about $655 \mathrm{~nm}$ following excitation at $450 \mathrm{~nm}$.

The biological effects and toxicity of QDs are up to many factors, such as exposure concentration, administration route, exposure time, immune clearance ability, et al. The physical and chemical properties (chemical composition, particle size, shape and structure, surface modification and charge, etc.) of QDs will also affect their biological effects after they enter the body. It is well known that male reproductive system is more sensitive and vulnerable to various stress such as heavy metals, exogenous compounds and NPs than other organ systems[15, 16]. Amiri et al. reported that intraperitoneal injection of $40 \mathrm{mg} / \mathrm{kg}$ CdSe/ZnS QDs could lead to the reduction of testicular lamina propria, the destruction in interstitial tissue, deformation of seminiferous tubules, the decrease in number of granulocytes, spermatocytes and spermatids in BALB/c mice [17]. However, the knowledge about the reproductive toxicity and developmental toxicity induced by QDs remain insufficiency. In this study, we systematically and comprehensively study the potential reproductive and developmental toxicity of CdSe/ZnS QDs towards male mice and their offspring after single intravenous injection.

\section{Biodistribution of CdSe/ZnS QDs in testes}

When QDs were injected intravenously into the body, they were transported to various organs along with blood circulation. In view of the good photoluminescent properties and stability of QDs, cryosection fluorescence microscopy technology was used to observe the biodistribution of QDs in testes. The representative results were shown in Figure 2. After exposure of $2 \mathrm{nmol} / \mathrm{kg}$ BW QDs, the fluorescence of QDs could be observed in testicular tissue sections, showing a red, bright and uniform punctate pattern. As time went on, the fluorescence intensity appeared to be decreasing gradually. No fluorescence was observed in the tissue sections of the control group. To quantitatively study the time-course of PL intensity of QDs in the testes, average PL intensity of each image field from multiple sections taken from several animals $(n=3)$ was measured and the results were shown in Figure. S1. The integrated PL intensity of QDs was the highest on the first day following administration, and then began to decline, but the fluorescence could still be detected on the $42^{\text {nd }}$ day. These results indicated that QDs could penetrate the blood-testis barrier (BTB) and then reached and accumulated in the testis structure through blood circulation. BTB is a kind of physical barrier between testicular blood vessels and seminiferous tubules, which can prevent some substances from entering into the seminiferous epithelium, form and maintain the microenvironment conducive to spermatogenesis. Noteworthy, there is increasing evidence that NPs can successfully penetrate the BTB and may have potential adverse effects on the reproductive system [18]. The accumulation of QDs in testicular tissue indicated that there was an interaction between QDs and biological barrier, leading to the uptake and distribution of QDs [19]. Yan et al. CdTe QDs could pass through the outer membrane of the silkworm's gonad, produce reactive oxygen species (ROS) in membranes of spermatocysts and internal germ cells, and affect the reproductive system [20]. Zhao et al. found that the fluorescent NPs derived from roasted pork could distribute rapidly in the testis of mice within 24 hours after oral administration [21]. Furthermore, tissue distribution of NPs largely depends on the size and surface modification. It has been reported that negative charged QDs are more likely to 
accumulate in organs because they may interact with and absorb to proteins in the blood [22]. Smaller NPs are also thought to be more likely to penetrate the BTB and then enter the testes. Park et al. reported small-size silver nanoparticles (AgNPs) could be distributed to testis while large-sized AgNPs were not detected in testicles when mice were orally given different size AgNPs [23]. In this study, we also found that the CdSe/ZnS QDs with negative charge and small particle size could pass through the BTB and distribute in testis tissue. After QDs cross the BTB and enter testicular tissue, they may interfere with male reproductive health which needs to be further evaluated.

\section{Body weight and organ weight/BW coefficients}

We monitored the effects of different exposure dose of CdTe/ZnS QDs on the behavior, food intake, urine, feces and body weight of mice over the whole experimental period. No abnormal changes were observed after exposure of QDs. Figure 3A presented the body weight of mice recorded within 42 days postinjection. The body weight of mice in the high-dose group, low-dose group and the control group showed comparable increasing trends. Bilateral testes and epididymides were dissected and weighted carefully when mice were sacrificed at different predetermined time points. Testicular index and epididymis index were calculated and the data was shown in Figure 3B and $3 \mathrm{C}$ respectively. No statistical significance was observed in testicular index and epididymis index among the high-dose group, low-dose group and the control group. These results suggested that CdTe/ZnS QDs had good biocompatibility and did not disturb the growth of mice. It is well known that the fluctuation of body weight and organ index is considered to be useful indicators for qualitative assessment of chemical toxicity in vivo. Normally, the ratio of organs to body weight is stable. After the animal is poisoned, the weight of the damaged organs can be altered, so the organ coefficient also changes. Consistently, many previous studies showed that QDs treatment would not cause changes in body weight or organ weight. For instance, Su et al. found that there was no significant changes in the body weight of mice over 80 days after the injection of $0.2 \mathrm{nmol}$ CdTe QDs,

although QDs could be distributed to major organs of mice such as liver, kidney, spleen [24]. Based on the data of body weight and organ index of mice obtained from different QDs, it is suggested that the overall toxicity of QDs in mice is relatively low

\section{Histopathological changes in testis and epididymis}

In order to study the reproductive toxicity of CdSe/ZnS QDs on male mice, the histopathology of testis and epididymis was analyzed to determine whether QDs itself or its degradation products could cause tissue lesions or inflammation. Mice treated with QDs or normal saline were sacrificed at 1, 7, 14, 28 and 42 day(s) post-injection. Both sides of testicles and epididymides were detached carefully, embedded in paraffin, sectioned and stained with hematoxylin and eosin. Representative images were shown in Figure 4. Mice treated with QDs exhibited normal seminiferous tubules with germinal epithelium and spermatogenesis when compared with the control group. Above results suggested that CdSe/ZnS QDs did not cause significant histopathological changes in testis and epididymis. The hispathological changes caused by NPs in vivo may be linked to the size, physicochemical properties and dosage. In a recent reports, Mata et al. reported that AgNPs and AuNPs with the size of 1-25 nm did not induce any 
pathological changes in the testes of Wistar rats after 28 days of continuous oral administration [25]. However, Kong et al. reported that nickel NPs with the size of $90 \mathrm{~nm}$ could lead to exfoliation of epithelial cells, cell disarrangement, apoptosis and death in seminiferous tubule when rats were treated with a higher dose (45 mg/kg BW) [26]. TUENL assay were used to observe the apoptosis cells of testis in this study. As shown in Figure 5, the apoptotic cells were labeled green by FITC and mainly located in the Leydig of testis. The apoptotic index on Day 1 and 14 of high-dose QDs group was significantly higher than that of the control group. The results shows that although QDs had no adverse effect on the tissue structure in testes, they caused apoptosis of Leydig cells on Day 1 and 14, which could recover on Day 28.

\section{Changes in sex hormone levels}

While histology provided macroscopic and visual evidence, detection of serum hormone levels was critical to evaluate the reproductive toxicity of CdSe/ZnS QDs on male mice. The hypothalamic pituitary - gonadal (HPG) axis is a branch that controls the secretion of sex hormones. Individually among males, the hypothalamus secretes gonadotropin releasing hormone $(\mathrm{GnRH})$, which is transported to the pituitary, making the pituitary secrete and produce LH and FSH. Finally these hormones are transported to testes via the blood. The process of spermatogenesis is regulated by all hormones on the HGF axis. LH stimulates Leydig cells to release T, while FSH and T stimulates Sertoli cells to regulate spermatogenesis by secreting various factors affecting Leydig cell function [27, 28]. The HPG axis of male is regulated by many factors. Exposure to environmental toxins may lead to changes in spermatogenesis and fertility [29]. In the present study, levels of serum T, FSH and LH at different sampling times after administration were measured and the results were shown in Figure 6(A-C). Serum LH levels exhibited time-dependent changes. The increase in LH levels in high-dose QDs group on Day 14 was observed initially compared with the low-dose QDs group and control group. However, there were no differences in LH levels among the three groups on Day 28 and Day 42. In addition, no statistical differences were observed in serum FHS levels and T levels among the high-dose QDs group, low-dose QDs group and the control group at throughout the observation period. Only high dose QDs can affect serum LH level in a short period of time, and then quickly return to normal level, while FSH level and T level did not affect by QDs under our exposure conditions. The above results indicated that the accumulation of QDs in male mice had little effect on the physiological function of HGF axis in mice.

\section{Effects on the quality of sperm}

Spermatogenesis is a complicated process which includes the proliferation and differentiation of spermatogonia, meiosis, and spermatogenesis [30]. Spermatozoa are produced in the seminiferous tubules of mouse testes and transported to the epididymides for maturation. The quality of epididymal sperm directly affects the reproductive capacity of human and animal and the health of offspring. It has been reported that nanomaterials can affect spermatogenesis, resulting in abnormal sperm morphology and low sperm function [9, 31]. Zhang et al. reported that $\mathrm{Mn}_{3} \mathrm{O}_{4} \mathrm{NPs}$ with the size of $20 \mathrm{~nm}$ could significantly reduce the sperm quality of rats, and ultimately lead to the decline in fertility after repeated 
intravenous injection for 120 days [32]. Describing the movement parameters of each sperm under a microscope can comprehensively evaluate sperm quality. Studies have shown that BCF, LIN and VCL are sensitive indexes of male reproductive toxicity. The changes of these parameters can indirectly reflect the activation of sperm in vivo under the condition of capacitation in vitro, which is related to the penetration of oocytes [26, 33]. In order to determine the toxic effect of CdSe/ZnS QDs on spermatogenesis, sperm was collected from the cauda epididymis of mice at 28 and 42 days post-injection, and the sperm quality was detected in the present study. As shown in Figure 7(A-J), the sperm motility of mice in QDs exposed group was significantly higher than that of the control group on Day 28 and Day 42. The MAD of sperm in high-dose QDs group decreased on Day 28 post-injection, while there was no significant difference between the low-dose QDs group and the control group at the same sampling time. In addition, the STR, LIN, WOB, VCL, VSL, VAP, ALH and BCF from high-dose and low-dose QDs exposed mice exhibited similarity to those of control mice. We also examined the serum acrosin level and sperm acrosome integrity after exposed to QDs. The detection results of serum acrosin were shown in Figure 7K. Serum acrosin levels of mice in low-dose QDs group on Day 14 and 28 were significantly higher than that of the control group. Levels of serum acrosin in high-dose QDs group were consistent with that in the control group. Representative images of acrosome integrity determination were shown in Figure $7 \mathrm{~L}$ and no obvious differences were observed between QDs exposed groups and the control group. Taken together, the above results indicated that CdSe/ZnS QDs had no adverse effect on sperm quality and sperm acrosome integrity.

\section{Assessment of fertility and offspring development}

The formation and maturation period of mouse sperm is about 35 days [34]. During this period, exogenous chemicals may interfere with testicular spermatogenesis and epididymal sperm maturation, resulting in abnormal reproductive capacity of male mice or developmental disorders of offspring mice [35]. Zhou et al. found that the number and quality of sperm decreased, leading to a significant reduction

in fertility after the male rats were treated with $10 \mathrm{mg} / \mathrm{kg} /$ week PbSe-NPs for 60 days [36]. However, some studies have found that nanomaterials have no adverse effects on male reproductive and developmental abilities. Zhang et al. reported that graphene QDs had no obvious effects on the structure and physiological function of testis and epididymis of male mice, and had no adverse effect on the growth and development of offspring after the mice were exposed to graphene QDs via oral gavage or intravenous injection [37].

In this study, we evaluated the fertility and offspring development of male mice after intravenous injection of different concentrations of CdSe/ZnS QDs. Seven male mice in each group were housed with unexposed female mice at the sex ratio of 1:1 on Day 35 after exposed QDs or saline injection. The results of fertility and offspring development were presented in Figure 8. Six of the seven females in each group were pregnant, exhibited normal parturition and gave birth to pups successfully. No significant differences were observed in the offspring numbers and average body weight at 0-24 $\mathrm{h}$ after birth. In order to evaluate the development of offspring more systematically, the body weight of offspring was recorded every five days, and the data were shown in Figure 8C. The body weight of pups in the low-dose 
QDs group increased from $(1.84 \pm 0.31) \mathrm{g}$ (PND 1) to $(19.35 \pm 1.49) \mathrm{g}$ (PND 30), which was nearly the same as that of the control group. However, the growth rate of pups in the high-dose QDs group was significantly lower than that in the control group from PND 20, which resulted statistical differences in the body weight of pups between the high-dose QDs group and the control group. It should be pointed out that the offspring of all groups of mice did not die naturally during the 30 day observation period. On PND 10, 20 and 30, one pup was randomly selected from each litter. Main organs include heart, liver, spleen, lung, kidney and brain were dissected carefully. The organ index was calculated and the results were shown in Figure 8(D-F). No significant differences were observed in the organ index of main organs of offspring on PND 10 among the three groups. However, there were significant differences in liver and spleen index of offspring between QDs-exposed groups and the control group on PND 20. More organs including heart, kidney and brain also showed statistical differences in organ index on PND 30 between QDs-exposed groups and the control group. It suggested that CdSe/ZnS QDs had adverse effects on the growth of offspring mice.

Furthermore, main hematological parameters, serum biochemical parameters and histopathology of the offspring at different times after birth were also measured and the results were shown in Figure 9 and Figure 10. Hematological examination results showed that the RBC levels and HGB levels of the pups in QDs-exposed groups decreased significantly on PND 20. Serum biochemical parameters showed that ALT levels, UREA levels on PND 20 and UREA levels on PND 30 of the pups in high-dose QDs groups were significantly changed when compared with those of the control group. It suggested that exposure of high dose QDs may have adverse effects on the liver and kidney function of the offspring. From the results of histopathological examination, no hydropic degeneration was observed in the cardiac muscle tissues, no inflammatory infiltrates were observed in the liver tissues, no hyperplasia or pulmonary fibrosis was observed in the spleen and lung tissues, no obvious pathological changes were observed in the kidney and brain samples. Overall, there were no apparent histopathological abnormalities in the main organs of the offspring after the male mice were treated with QDs. All these results demonstrated that the fertility of male mice was not affected after the male mice were administrated CdSe/ZnS QDs via intravenous injection. However, there was a dose-dependent effect on the development of offspring, which was mainly reflected in the slow growth of offspring, the alteration of organ index of main organs, the abnormality of liver and kidney function parameters of parental male mice exposed to high concentration of QDs.

\section{Conclusions}

We mainly evaluated the male reproductive toxicity and developmental toxicity of CdSe/ZnS QDs after a single intravenous injection in vivo. The QDs could cross over the BTB and rapidly distribute in the testis. With the extension of observation time, the fluorescence intensity of QDs decreased gradually, while it could be detected on Day 42 post-injection. Histopathological examination results showed that the QDs had no adverse effect on the structure of testis and epididymis, but TUNEL assay showed that high-dose QDs could induce apoptosis of Leydig cells in testis at an early stage which could recover as time went on. There were no significant differences in survival state, body weight organ index of testis and epididymis, sex hormones levels, sperm quality, sperm acrosome integrity and fertility of male mice 
among high-dose QDs group, low-dose QDs group and the control group. However, it had an obvious effect on the development of offspring, which was mainly manifested in the slow growth of offspring, changes of organ index of main organs, and the abnormality of liver and kidney function parameters when parental male mice exposed to high-dose of CdSe/ZnS QDs. These data demonstrated that CdSe/ZnS QDs administered via intravenous injection produce no discernible toxic effects on male reproductive ability, but will affect the healthy growth of offspring, which need to be paid enough attention. Given the significant potential of QDs for biomedical detection, drug delivery, and gene delivery, we hope safer QDs will be designed and synthesized, which can greatly benefit future clinical applications of QDs.

\section{Methods}

\section{Characterization of QDs}

CdSe/ZnS QDs (No. Q21321MP, Thermo Fisher Scientific, USA) were coated with a polymer layer and terminated with carboxyl groups. Morphology images of CdSe/ZnS QDs were analyzed by transmission electron microscopy (TEM) (JEM-1230, JEOL LTD, Japan) with an acceleration voltage of $120 \mathrm{kV}$. Dynamic light scattering (DLS) characterization and zeta potential was measured by zeta potential and particle size analyzer (Brookhaven Instruments Inc., USA). Ultraviolet-visible spectroscopy (UV-Vis) absorption spectra and PL spectra were measured by UV/Vis spectrophotometer (DU720, Beckman Coulter Inc., USA) and fluorescence spectrophotometer (F-4600, HITACHI, Japan), respectively. All these characterizations were kept stable at room temperature for several months.

\section{Animals}

Four to six weeks old female and male BALB/c mice were purchased from the Medical Laboratory Animal Center (Guangzhou, China) and housed in independent ventilation cages in the animal room (relative humidity at $60 \pm 10 \%$ and a 12 hour light/dark circle). Distilled water and sterilized food were available ad libitum. All animal treatments and experimental protocols were approved by the Laboratory Animals Center and the Experimental Animal Ethics Committee of Shenzhen University (Permit No. AEWC201412012).

\section{QDs exposure methods and sample collection}

After acclimation for 1 week in the animal facility, male mice were randomly divided into 3 groups according to the dosage of tail vein injection, high dose group ( $2 \mathrm{nmol} / \mathrm{kg} \mathrm{BW}$ of CdSe/ZnS QDs), low dose group ( $0.2 \mathrm{nmol} / \mathrm{kg} \mathrm{BW}$ of CdSe/ZnS QDs), and control group (the same volume of normal saline, $100 \mu \mathrm{L}$ per mouse). Body weight, behavior, mental status, food intake, feces were recorded carefully and regularly after injection. At predetermined time points (1, 7, 14, 28 and 42 days) after administration, seven mice from each group were anesthetized with isoflurane. Blood was harvested from the posterior orbital venous plexus of mice and serum samples were obtained by centrifugation at $3500 \mathrm{rpm}$ for 10 min. Then the mice were sacrificed by cervical dislocation. Bilateral testes and epididymides were excised 
and weight for organ index calculations (organ weight/body weight). Parts of the organs were fixed in tissue fixative solution (Wexis, China) for further histological examination, parts were embedded in optimal cutting temperature compound (OCT, Sakura Finetek, USA) for tissue fluorescence imaging. Other fresh tissue samples were stored at $-80^{\circ} \mathrm{C}$.

\section{Fertility evaluation}

To evaluate the effect of CdSe/ZnS QDs on the fertility of male mice, seven male mice from each group were housed with non-exposed female mice at a sex ratio of 1:1 on Day 35 after injection of QDs or normal saline. Females' vaginal smears were examined to determine positive mating next morning. Once fertilization was confirmed, female mice were observed daily until days 19-21 to determine the delivery time of pregnancy. Females were allowed to deliver spontaneously and nurse their pups until postnatal day 20 (PND 20). Pup numbers at 0-24 h, pup weight after birth were recorded carefully. The schedule of QDs exposure and sample collection after exposure was shown in Figure 1A.

\section{Evaluation of health status of offspring produced by QDs-exposed mice}

The weight and morphology of pups were recorded daily after birth. Offspring images during growth were captured using a mobile phone (Mi $6 \mathrm{X}$, Xiaomi Technology Co., Ltd, China). At the $20^{\text {th }}$ and $30^{\text {th }}$ day after birth, one pup was randomly selected from each litter, anesthetized with isoflurane, and blood samples were collected for hematological and biochemical analysis. Following blood collection, pubs were sacrificed and the main organs (heart, liver, spleen, lung, kidney and brain) were excised and weight for organ indices calculation. Organs were fixed in tissue fixative solution for histological examination.

\section{Tissue fluorescence imaging and histopathological examination}

In order to observe the distribution of QDs in testis and epididymis, the testis and epididymis were fixed in OCT embedding compound, and frozen at $-80^{\circ} \mathrm{C}$. Frozen sections $(5 \mu \mathrm{m})$ were cut using a freezing microtome (CM3050S, Leica, Germany). Fluorescence microscopic imaging of QDs was observed under a fluorescent microscope (Axio Observer, ZEISS, Germany).

For histopathological analysis, tissues fixed in tissue fixative solution were dehydrated gradiently with different concentration of alcohol in the automatic tissue dehydrator (APS300S, Leica, Germany), embedded in paraffin blocks by paraffin embedding station (Leica, Germany), then cut into $5 \mu \mathrm{m}$ thin slices by the ultra-thin semiautomatic microtome (RM2236, Leica, Germany) and adhered to the slides. After staining with Hematoxylin and Eosin (H\&E), the tissue morphology was imaged under an optical microscope (Axio Observer, ZEISS, Germany).

\section{ELISA}

The content of acrosin, T, LH and FSH in the serum of QDs-exposed male mice groups and the control group were determined by enzyme linked immunosorbent assay (ELISA) according to the manufacturer's protocol (Shanghai Jianglai Biotechnology Co., Ltd, China). 


\section{TUNEL assay}

TUNEL analysis was performed to measure the degree of cellular apoptosis in testicular tissue of mice using an TUNEL FITC apoptosis detection kit (Vazyme biotech co., Ltd, China) according to the manufacturer's instructions. The results were obtained under a fluorescent microscope (Axio Observer, ZEISS, Germany). The nuclei of normal cells were stained blue by DAPI and the apoptotic cells were labeled green by FITC. The average number of TUNEL positive apoptotic cells was measured. Apoptotic index in each group was expressed by the ratio of apoptotic cells to DAPI positive cells.

\section{Semen evaluation}

On Day 28 and Day 42, the left cauda epididymis of mice in QDs exposed group and control group was dissected, cut into pieces, immersed in $3 \mathrm{~mL}$ Roswell Park Memorial Institute (RPMI-1640) medium containing $10 \%$ fetal bovine serum (FBS) and incubated at $37^{\circ} \mathrm{C}$ to disperse sperm into the medium. Parameters of sperm quality were measured using an automatic sperm analyzer (Nanning Songjing Tianlun Biotechnology Co., Ltd, China), including sperm motility, straightness (STR), linearity (LIN), Wobble (WOB), curvilinear velocity (VCL), straight-line velocity (VSL), average path velocity (VAP), amplitude of lateral head displacement (ALH), beat-cross frequency (BCF), and average movement angle (MAD). Acrosome integrity was evaluated by rose Bengal and Bismark brown $\mathrm{Y}$ staining according to the commercial kit (GENMED, China).

\section{Statistical analysis}

All statistical analysis was performed by SPSS 22.0 statistical software packages. Figures were drawn with GraphPad Prism 8.0 software package. Data were expressed as the mean \pm standard deviation (SD). Differences between groups were compared by one-way ANOVA. $P<0.05$ was considered significant.

\section{Declarations}

\section{Ethical approval and Consent to participate}

Animals were treated humanely and all experimental protocols were approved by the Committee on Animal Use and Care of Shenzhen University. All the methods in the present study were performed according to the approved guidelines.

\section{Consent for publication}

Not applicable.

\section{Availability of data and materials}

The datasets used and/or analyzed during this study are available from the corresponding authors on reasonable request. 


\section{Competing interests}

No conflict of interest in the submission of this manuscript is declared.

\section{Funding}

This study was funded by the National Natural Science Foundation of China (NSFC) under grant 21677102, 61935012 and 31671491, Guangdong Basic and Applied Basic Research Foundation under grant 2019A1515110342, Shenzhen Science and Technology project under grant JCYJ20190808153803592 and JCYJ20170817093725277.

\section{Author' Contributions}

$L L, X L, T C, K L, Z Y, D L$ and $Y C$ performed the experiments, $G X, X W$ and $G L$ designed the experiments. $L L$ and $\mathrm{XL}$ drafted the manuscript. TC, GX, XW and GL contributed to the data analysis, manuscript preparation, and manuscript review and revision process. All authors read and approved the final manuscript.

\section{Acknowledgements}

We thank the Instrumental Analysis Center of Shenzhen University (Xili Campus) for their assistance in our experiments.

\section{References}

1. Pandey S, Bodas D. High-quality quantum dots for multiplexed bioimaging: A critical review. Adv Colloid Interface Sci. 2020;278:102137; doi: 10.1016/j.cis.2020.102137. https://www.ncbi.nlm.nih.gov/pubmed/32171116.

2. Wu YW, Wang QY, Wu TT, Liu W, Nan HX, Xu SH, et al. Detection and Imaging of Hydrogen Sulfide in Lysosomes of Living Cells with Activatable Fluorescent Quantum Dots. Acs Applied Materials \& Interfaces. 2018;10 50:43472-81; doi: 10.1021/acsami.8b16971. <Go to ISI>://WOS:000454383500020.

3. Wang LW, Peng CW, Chen C, Li Y. Quantum dots-based tissue and in vivo imaging in breast cancer researches: current status and future perspectives. Breast Cancer Res Treat. 2015;151 1:7-17; doi: 10.1007/s10549-015-3363-x. https://www.ncbi.nlm.nih.gov/pubmed/25833213.

4. Kamaly N, Xiao Z, Valencia PM, Radovic-Moreno AF, Farokhzad OC. Targeted polymeric therapeutic nanoparticles: design, development and clinical translation. Chem Soc Rev. 2012;41 7:2971-3010; doi: 10.1039/c2cs15344k. https://www.ncbi.nlm.nih.gov/pubmed/22388185.

5. Yu Z, Hao R, Zhang L, Zhu Y. Effects of TiO2, SiO2, Ag and CdTe/CdS quantum dots nanoparticles on toxicity of cadmium towards Chlamydomonas reinhardtii. Ecotoxicol Environ Saf. 2018;156:75-86; doi: 10.1016/j.ecoenv.2018.03.007. https://www.ncbi.nlm.nih.gov/pubmed/29533210. 
6. Liang X, Wu T, Wang Y, Wei T, Zou L, Bai C, et al. CdTe and CdTe@ZnS quantum dots induce IL-1ssmediated inflammation and pyroptosis in microglia. Toxicol In Vitro. 2020;65:104827; doi:

10.1016/j.tiv.2020.104827. https://www.ncbi.nIm.nih.gov/pubmed/32179110.

7. Strtak A, Sathiamoorthy S, Tang PS, Tsoi KM, Song F, Anderson JB, et al. Yeast Populations Evolve to Resist CdSe Quantum Dot Toxicity. Bioconjug Chem. 2017;28 4:1205-13; doi: 10.1021/acs.bioconjchem.7b00056. https://www.ncbi.nlm.nih.gov/pubmed/28152308.

8. Tarantola M, Schneider D, Sunnick E, Adam H, Pierrat S, Rosman C, et al. Cytotoxicity of metal and semiconductor nanoparticles indicated by cellular micromotility. Acs Nano. 2009;3 1:213-22; doi: 10.1021/nn800721j. https://www.ncbi.nlm.nih.gov/pubmed/19206269.

9. Lan Z, Yang WX. Nanoparticles and spermatogenesis: how do nanoparticles affect spermatogenesis and penetrate the blood-testis barrier. Nanomedicine-Uk. 2012;7 4:579-96; doi: 10.2217/nnm.12.20. $<$ Go to ISI>://WOS:000303076000014.

10. Bai YH, Zhang Y, Zhang JP, Mu QX, Zhang WD, Butch ER, et al. Repeated administrations of carbon nanotubes in male mice cause reversible testis damage without affecting fertility. Nat Nanotechnol. 2010;5 9:683-9; doi: 10.1038/Nnano.2010.153. <Go to ISI>://WOS:000281603400016.

11. Widlak W, Vydra N. The Role of Heat Shock Factors in Mammalian Spermatogenesis. Adv Anat Embryol Cell Biol. 2017;222:45-65; doi: 10.1007/978-3-319-51409-3_3. https://www.ncbi.nlm.nih.gov/pubmed/28389750.

12. Qu Y, Li W, Zhou YL, Liu XF, Zhang LL, Wang LM, et al. Full Assessment of Fate and Physiological Behavior of Quantum Dots Utilizing Caenorhabditis elegans as a Model Organism. Nano Letters. 2011;11 8:3174-83; doi: 10.1021/n|201391e. <Go to ISI>://WOS:000293665600021. https://pubs.acs.org/doi/pdf/10.1021/nl201391e.

13. Li XH, Yang XR, Yuwen LH, Yang WJ, Weng LX, Teng ZG, et al. Evaluation of toxic effects of CdTe quantum dots on the reproductive system in adult male mice. Biomaterials. 2016;96:24-32; doi: 10.1016/j.biomaterials.2016.04.014. <Go to ISI >://WOS:000377736800003.

14. Wang X, Tian J, Yong K-T, Zhu X, Lin MC-M, Jiang W, et al. Immunotoxicity assessment of CdSe/ZnS quantum dots in macrophages, lymphocytes and BALB/c mice. Journal of Nanobiotechnology. 2016;14; doi: 10.1186/s12951-016-0162-4. <Go to |SI>://WOS:000369481500001. https://jnanobiotechnology.biomedcentral.com/track/pdf/10.1186/s12951-016-0162-4.

15. Das J, Choi YJ, Song H, Kim JH. Potential toxicity of engineered nanoparticles in mammalian germ cells and developing embryos: treatment strategies and anticipated applications of nanoparticles in gene delivery. Hum Reprod Update. 2016;22 5:588-619; doi: 10.1093/humupd/dmw020. <Go to ISI>://WOS:000383902200004.

16. Joo SH, Aggarwal S. Factors impacting the interactions of engineered nanoparticles with bacterial cells and biofilms: Mechanistic insights and state of knowledge. J Environ Manage. 2018;225:62-74; doi: 10.1016/j.jenvman.2018.07.084. <Go to ISI>://WOS:000445988400007.

17. Amiri G, Valipoor A, Parivar K, Modaresi M, Noori A, Gharamaleki H, et al. Comparison of Toxicity of CdSe: ZnS Quantum Dots on Male Reproductive System in Different Stages of Development in Mice. 
Int J Fertil Steril. 2016;9 4:512-20. <Go to ISI>://WOS:000367181000012.

18. Brohi RD, Wang L, Talpur HS, Wu D, Khan FA, Bhattarai D, et al. Toxicity of Nanoparticles on the Reproductive System in Animal Models: A Review. Front Pharmacol. 2017;8; doi: ARTN 606 10.3389/fphar.2017.00606. <Go to ISI>://WOS:000409382600002.

19. Wang RL, Song B, Wu JR, Zhang YL, Chen AJ, Shao LQ. Potential adverse effects of nanoparticles on the reproductive system. Int J Nanomed. 2018;13:8487-506; doi: 10.2147/ljn.S170723. <Go to ISI>://WOS:000452753500004.

20. Yan SQ, Xing R, Zhou YF, Li KL, Su YY, Qiu JF, et al. Reproductive toxicity and gender differences induced by cadmium telluride quantum dots in an invertebrate model organism. Scientific Reports. 2016;6; doi: ARTN 34182 10.1038/srep34182. <Go to ISI>://WOS:000384086800001.

21. Zhao X, Shan SH, Li JQ, Cao L, Lv J, Tan MQ. Assessment of potential toxicity of foodborne fluorescent nanoparticles from roasted pork. Nanotoxicology. 2019;13 10:1310-23; doi: 10.1080/17435390.2019.1652943. <Go to ISI>://WOS:000483163800001.

22. Liu QQ, Li HX, Xia QY, Liu Y, Xiao K. Role of surface charge in determining the biological effects of CdSe/ZnS quantum dots. Int J Nanomed. 2015;10:7073-88; doi: 10.2147/ljn.S94543. <Go to ISI>://WOS:000365195200001.

23. Park EJ, Bae E, Yi J, Kim Y, Choi K, Lee SH, et al. Repeated-dose toxicity and inflammatory responses in mice by oral administration of silver nanoparticles. Environmental Toxicology and Pharmacology. 2010;30 2:162-8; doi: 10.1016/j.etap.2010.05.004. <Go to ISI>://WOS:000281339500011.

24. Su YY, Peng F, Jiang ZY, Zhong YL, Lu YM, Jiang XX, et al. In vivo distribution, pharmacokinetics, and toxicity of aqueous synthesized cadmium-containing quantum dots. Biomaterials. 2011;32 25:585562; doi: 10.1016/j.biomaterials.2011.04.063. <Go to ISI>://WOS:000292714700013.

25. Mata R, Nakkala JR, Chandra VK, Raja K, Sadras SR. In vivo bio-distribution, clearance and toxicity assessment of biogenic silver and gold nanoparticles synthesized from Abutilon indicum in Wistar rats. J Trace Elem Med Bio. 2018;48:157-65; doi: 10.1016/j.jtemb.2018.03.015. <Go to ISI>://WOS:000438326700023.

26. Kong L, Tang M, Zhang T, Wang DY, Hu K, Lu WQ, et al. Nickel Nanoparticles Exposure and Reproductive Toxicity in Healthy Adult Rats. Int J Mol Sci. 2014;15 11:21253-69; doi: 10.3390/ijms151121253. <Go to ISI>://WOS:000345529200111.

27. Huleihel M, Lunenfeld E. Regulation of spermatogenesis by paracrine/autocrine testicular factors. Asian J Androl. 2004;6 3:259-68. <Go to ISI>://WOS:000223907600011.

28. Li WQ, Wang F, Liu ZM, Wang YC, Wang J, Sun F. Gold Nanoparticles Elevate Plasma Testosterone Levels in Male Mice without Affecting Fertility. Small. 2013;9 9-10:1708-14; doi: 10.1002/smll.201201079. <Go to ISI>://WOS:000319076000025.

29. Liu JY, Yang X, Sun XD, Zhuang CC, Xu FB, Li YF. Suppressive Effects of Copper Sulfate Accumulation on the Spermatogenesis of Rats. Biological Trace Element Research. 2016;174 2:35661; doi: 10.1007/s12011-016-0710-7. <Go to ISI>://WOS:000387341800014. 
30. Pereira CD, Serrano JB, Martins F, Silva OABDE, Rebelo S. Nuclear envelope dynamics during mammalian spermatogenesis: new insights on male fertility. Biol Rev. 2019;94 4:1195-219; doi: 10.1111/brv.12498. <Go to ISI>://WOS:000474020700001.

31. Pinho AR, Rebelo S, Pereira MD. The Impact of Zinc Oxide Nanoparticles on Male (In)Fertility. Materials. 2020;13 4; doi: ARTN 849 10.3390/ma13040849. <Go to ISI>://WOS:000520419300040.

32. Zhang X, Yue ZK, Zhang HJ, Liu L, Zhou XM. Repeated administrations of Mn3O4 nanoparticles cause testis damage and fertility decrease through PPAR-signaling pathway. Nanotoxicology. 2020;14 3:326-40; doi: 10.1080/17435390.2019.1695976. <Go to ISI>://WOS:000506097800001.

33. Yuan C, Wang C, Gao SQ, Kong TT, Chen L, Li XF, et al. Effects of permethrin, cypermethrin and 3phenoxybenzoic acid on rat sperm motility in vitro evaluated with computer-assisted sperm analysis. Toxicology in Vitro. 2010;24 2:382-6; doi: 10.1016/j.tiv.2009.11.001. <Go to ISI>://WOS:000275991700005.

34. Xia XY, Wang L, Yang X, Hu YQ, Liu Q. Acute Damage to the Sperm Quality and Spermatogenesis in Male Mice Exposed to Curcumin-Loaded Nanoparticles. Int J Nanomed. 2020;15:1853-62; doi: 10.2147/ljn.S237254. <Go to ISI>://WOS:000519695200001.

35. Ban Z, Zhou QX, Sun AQ, Mu L, Hu XG. Screening Priority Factors Determining and Predicting the Reproductive Toxicity of Various Nanoparticles. Environmental Science \& Technology. 2018;52 17:9666-76; doi: 10.1021/acs.est.8b02757. <Go to ISI>://WOS:000444061100013.

36. Zhou QX, Yue ZK, Li QZ, Zhou RR, Liu L. Exposure to PbSe Nanoparticles and Male Reproductive Damage in a Rat Model. Environmental Science \& Technology. 2019;53 22:13408-16; doi: 10.1021/acs.est.9b03581. <Go to ISI :://WOS:000498279400046.

37. Zhang D, Zhang ZF, Wu Y, Fu K, Chen Y, Li WH, et al. Systematic evaluation of graphene quantum dot toxicity to male mouse sexual behaviors, reproductive and offspring health. Biomaterials. 2019;194:215-32; doi: 10.1016/j.biomaterials.2018.12.001. <Go to ISI>://WOS:000457504900019.

\section{Figures}


A

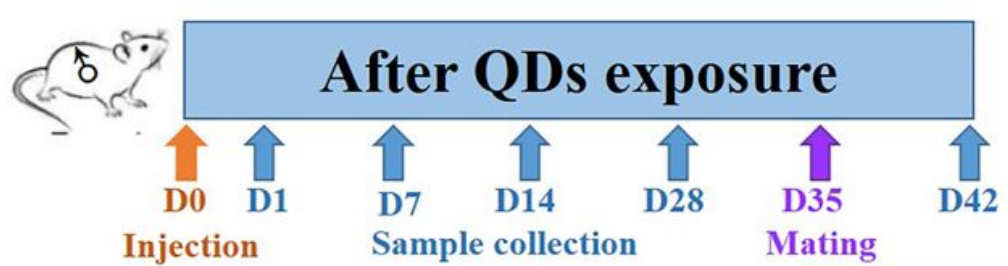

Injection Sample collection Mating

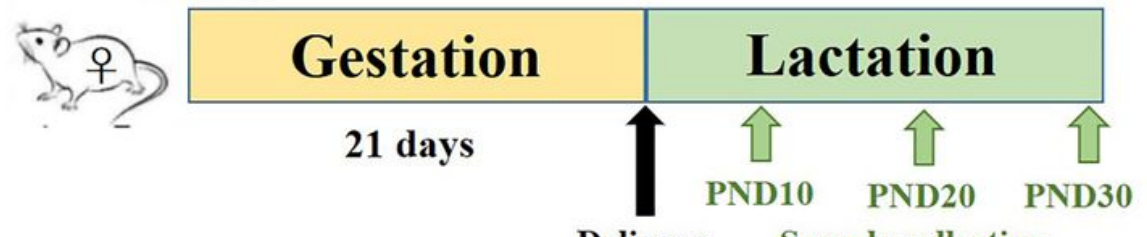

Delivery Sample collection

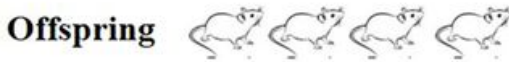

B

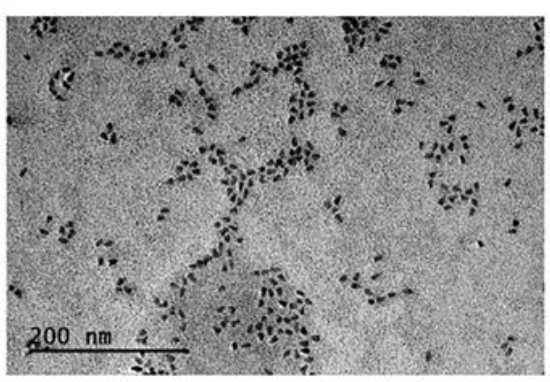

C

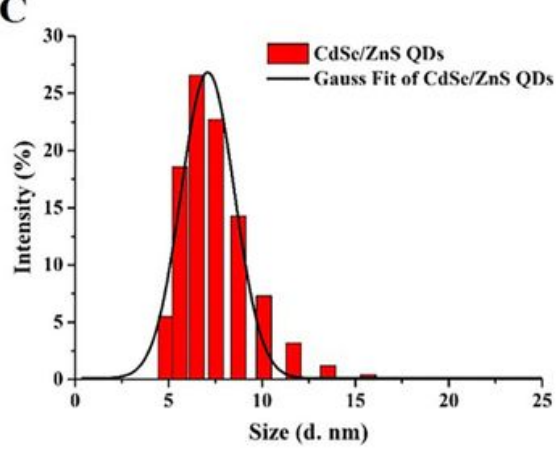

D

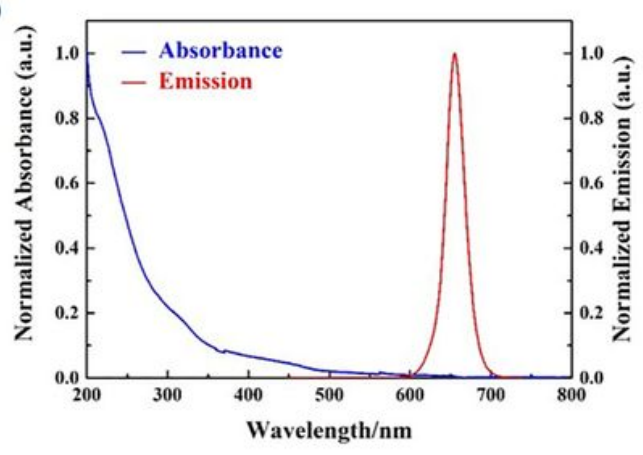

Figure 1

Schedule of experiments and characterization of CdSe/ZnS QDs. (A) Schedule of evaluation of CdSe / ZnS QDs on reproductive and offspring health in BALB / C male mice. (B) TEM image. (C) DLS. (D) Normalized absorption spectra and normalized PL spectra.

$2 \mathrm{nmol} / \mathrm{kg}$ QDs

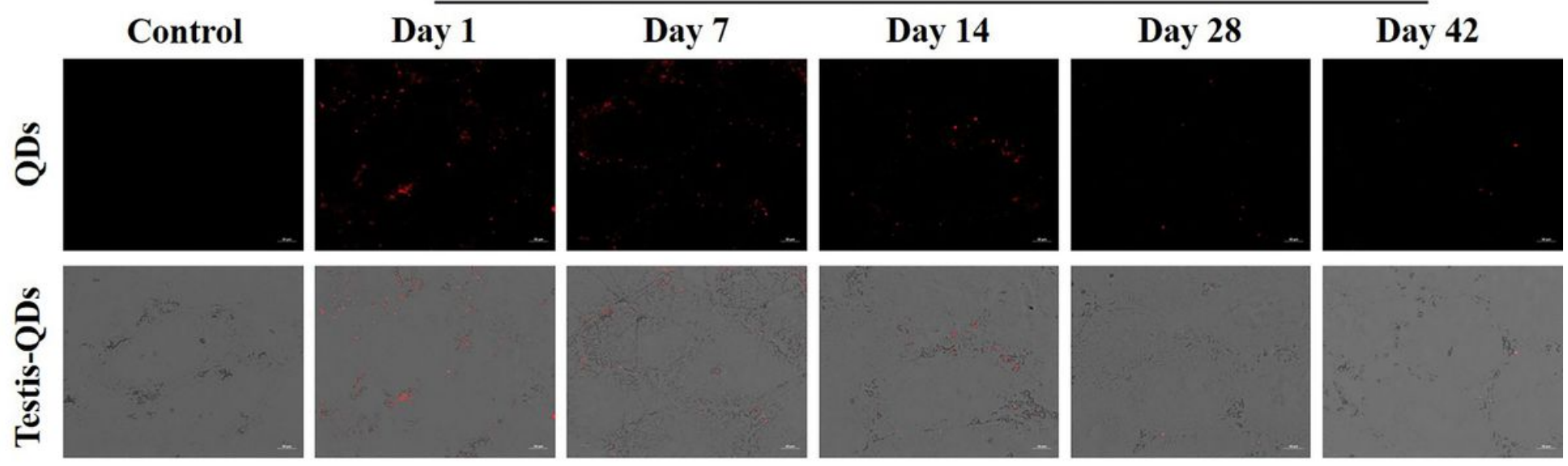

Figure 2

Representative fluorescence images of testicular tissue from mice on Day 1, 7, 14, 28 and 42 after they were treated with $2 \mathrm{nmol} / \mathrm{kg}$ BW CdSe/ZnS QDs or normal saline (scale bar: $50 \mu \mathrm{m}$ ). 

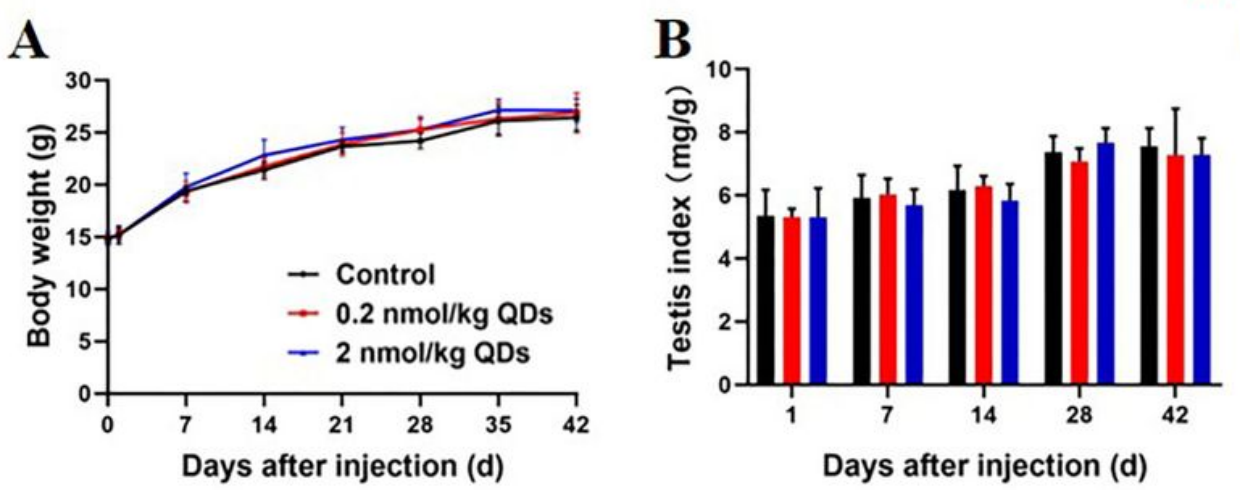

C

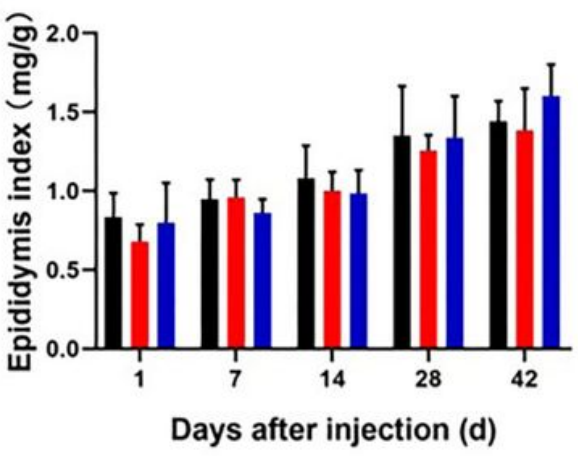

Figure 3

Effect of QDs on organ index of BALB/c mice during 42 days. (A) Body weight. (B) testis index . (C) epididymis index

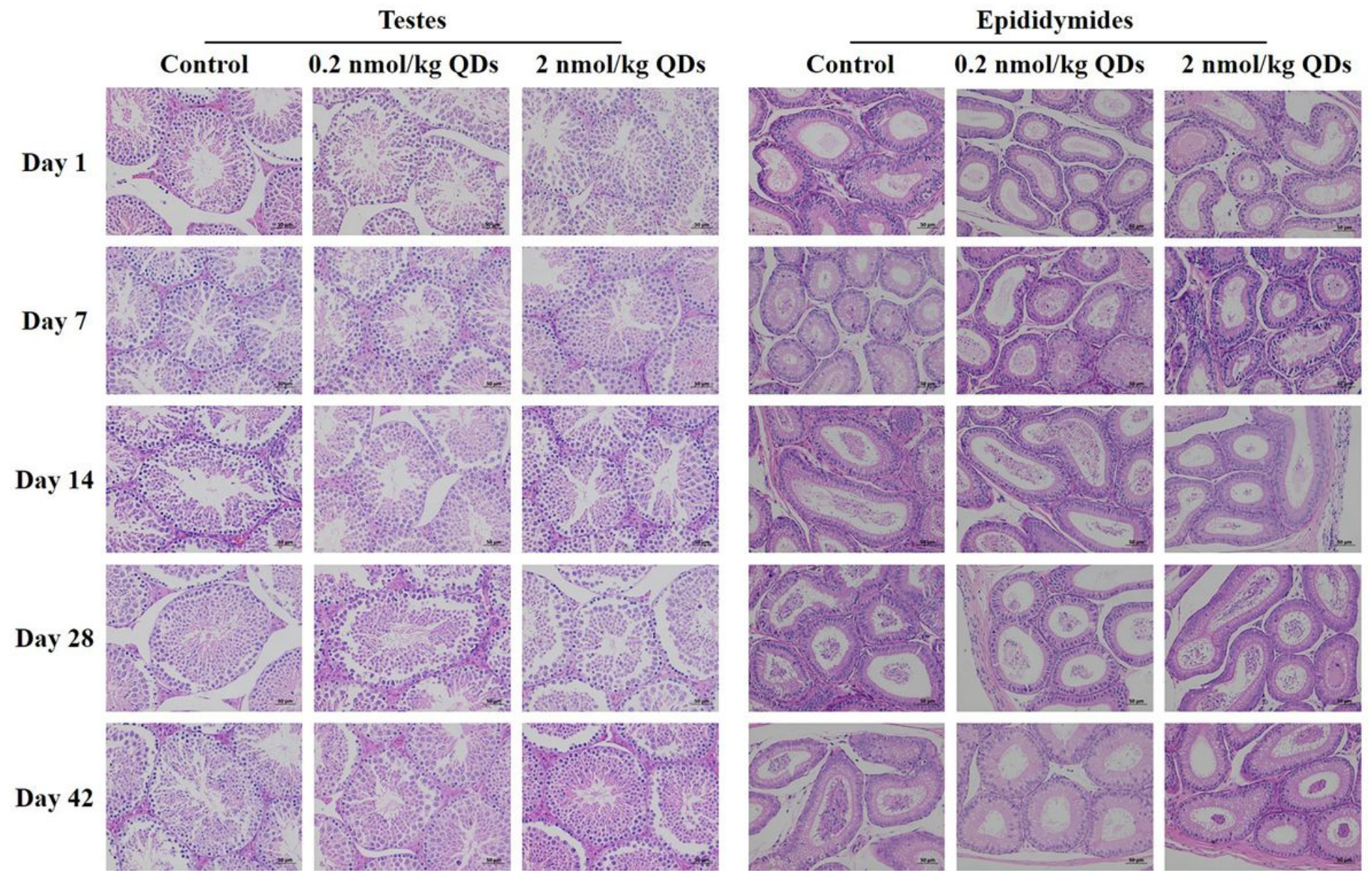

Figure 4

Representative H\&E staining images of testicular tissue and epididymal tissue of mice treated with 2 $\mathrm{nmol} / \mathrm{kg} \mathrm{BW}, 0.2 \mathrm{nmol} / \mathrm{kg} \mathrm{BW}$ CdSe/ZnS QDs or normal saline on Day 1, 7, 14, 28 and 42 (scale bar: 50 $\mu \mathrm{m})$. 


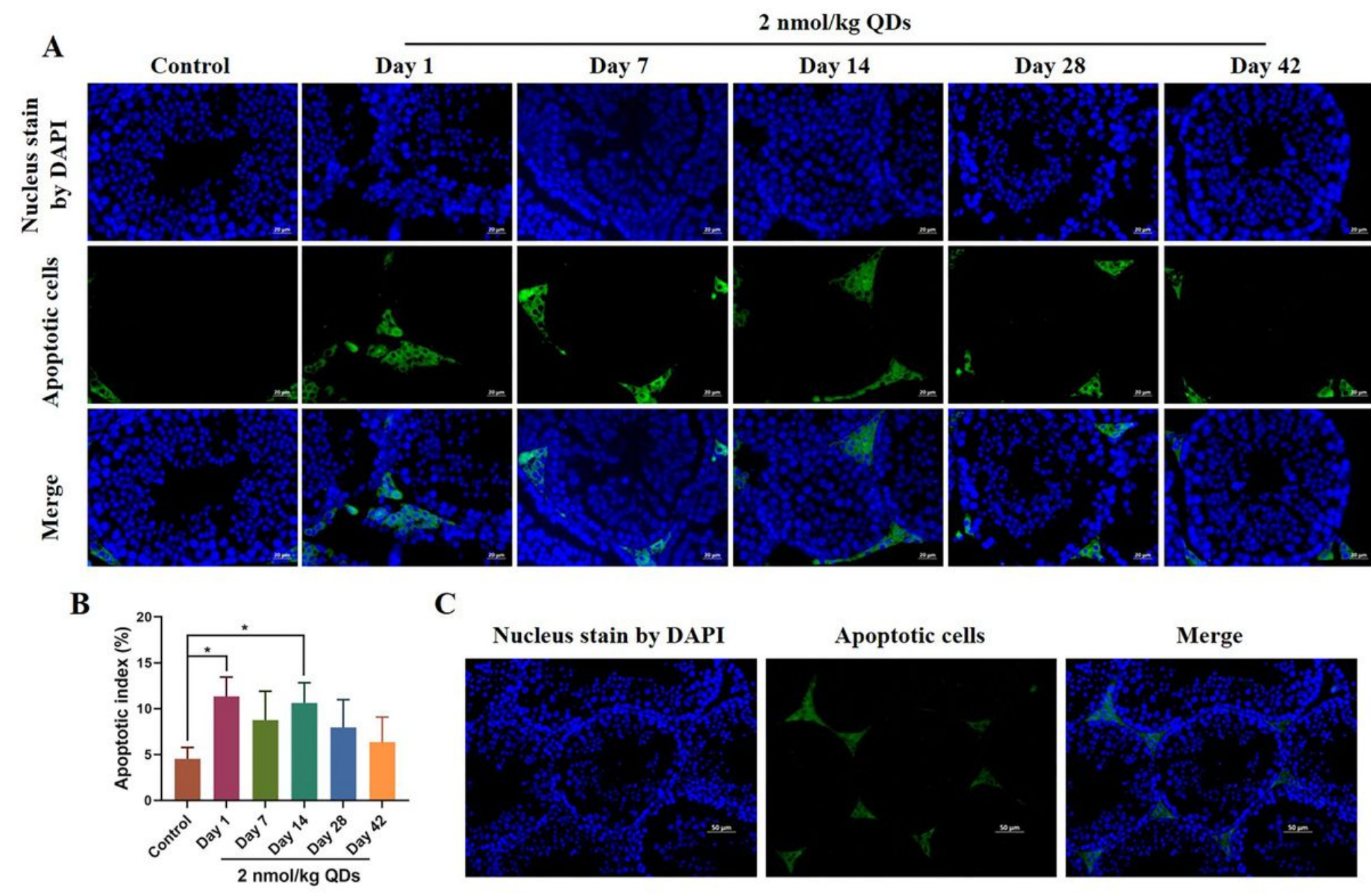

Figure 5

Effect of QDs on cell apoptosis detected by TUNEL assay. (A) Representative TUNEL images of testicular tissue of mice on Day 1, 7, 14, 28 and 42 after treated with $2 \mathrm{nmol} / \mathrm{kg} \mathrm{BW} \mathrm{CdSe/ZnS} \mathrm{QDs} \mathrm{or} \mathrm{normal}$ saline (scale bar: $20 \mu \mathrm{m}$ ). (B) Apoptotic index percentage. (C) Representative TUNEL images of testicular tissue of mice on Day 14 treated with $2 \mathrm{nmol} / \mathrm{kg}$ BW CdSe/ZnS QDs with the scale bar of $50 \mu \mathrm{m}$.

(*Significantly different compared to control group, $\mathrm{P}<0.05$.)

\section{Control \\ $0.2 \mathrm{nmol} / \mathrm{kg}$ QDs \\ $2 \mathrm{nmol} / \mathrm{kg}$ QDs}
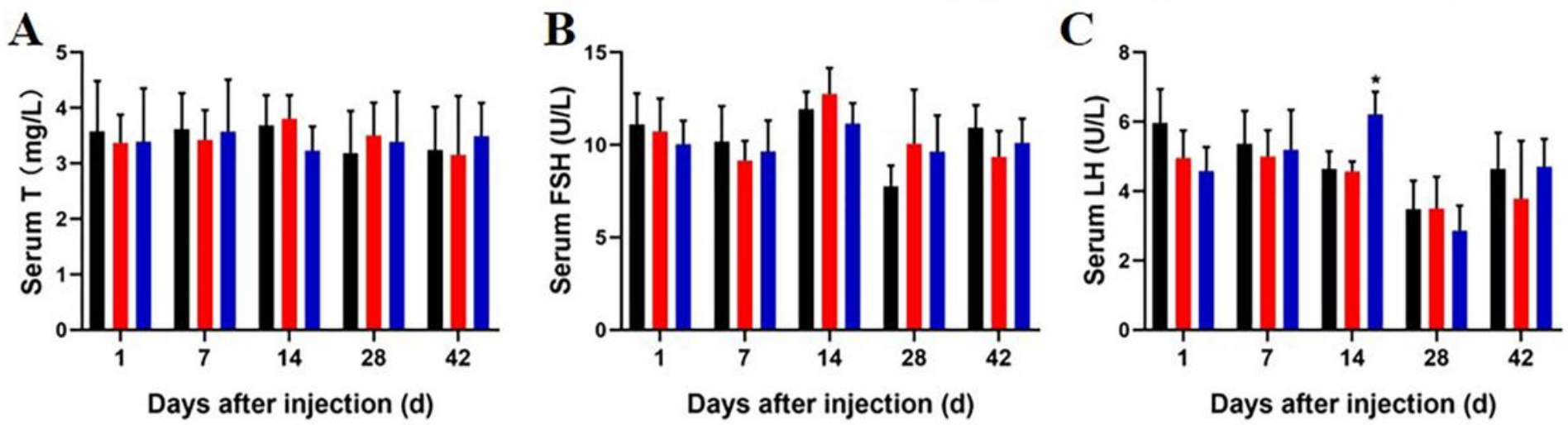

Figure 6 
Serum T levels (A), serum FSH levels (B) and serum LH levels (C) of mice on Day 1, 7, 14, 28 and 42 after treated with $2 \mathrm{nmol} / \mathrm{kg} \mathrm{BW}, 0.2 \mathrm{nmol} / \mathrm{kg} \mathrm{BW}$ CdSe/ZnS QDs or normal saline. (*Significantly different compared to control group at the same sampling time, $\mathrm{P}<0.05$.)

- Control $0.2 \mathrm{nmol} / \mathrm{kg}$ QDs
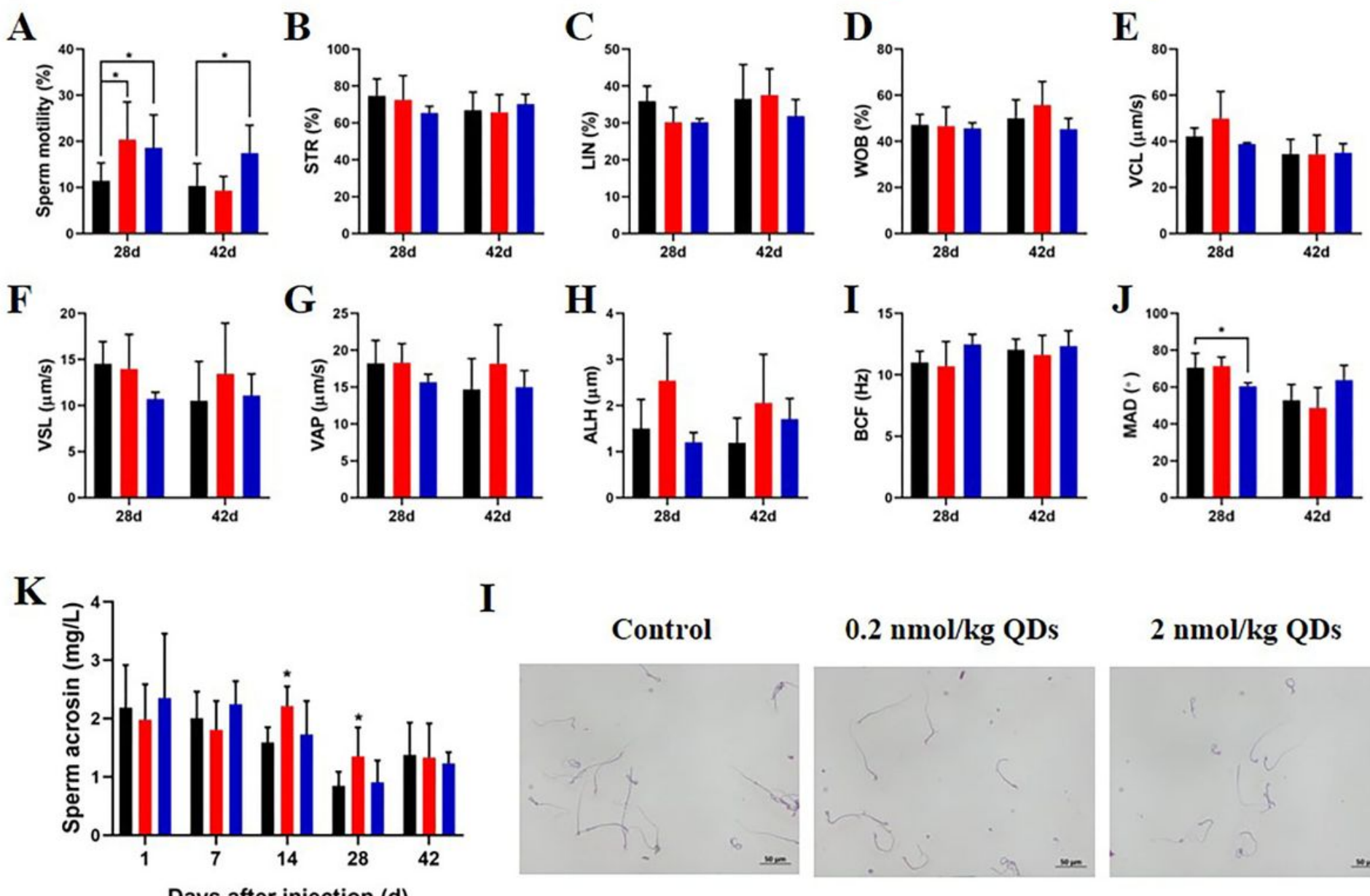

I

Control

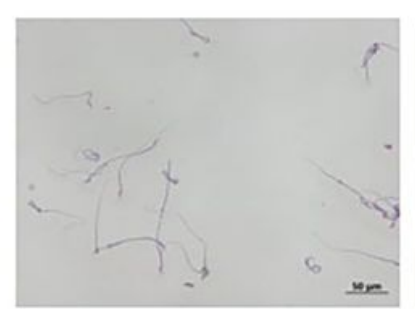

$0.2 \mathrm{nmol} / \mathrm{kg}$ QDs

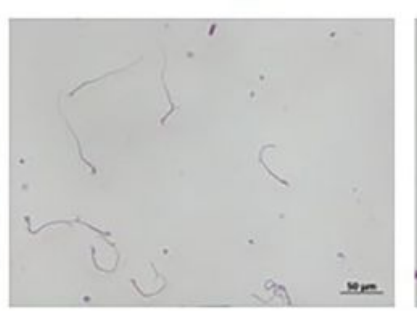

$2 \mathrm{nmol} / \mathrm{kg}$ QDs

\section{Figure 7}

Sperm quality and acrosome integrity. Sperm quality including sperm motility (A), STR (B), LIN (C), WOB (D), VCL (E), VSL (F), VPA (G), ALH (H), BCF (I) and MAD (J) of mice after treated with CdSe/ZnS QDs or normal saline on Day 28 and 42. (K) Serum sperm acrosin levels of mice on Day 1, 7, 14, 28 and 42 after treated with QDs or normal saline. $(L)$ Representative images of sperm acrosome integrity staining on Day 28 after administration. (scale bar: $50 \mu \mathrm{m}$. *Significantly different compared to control group at the same sampling time, $\mathrm{P}<0.05$.) 
A Mouse parents and their litter of offspring

(The males were housed with unexposed females on Day 35 after treatment)

\begin{tabular}{|c|c|c|c|c|c|}
\hline \multirow[t]{2}{*}{ Group } & \multirow{2}{*}{$\begin{array}{l}\text { Number of male } \\
\text { mice (the sex ratio of } \\
\text { female to male }=1: 1 \text { ) }\end{array}$} & \multirow[t]{2}{*}{$\begin{array}{l}\text { Number of } \\
\text { pregnant mice }\end{array}$} & \multicolumn{2}{|c|}{$\begin{array}{l}\text { Number of pups produced by the } \\
\text { mouse dams }\end{array}$} & \multirow{2}{*}{$\begin{array}{l}\text { Average body } \\
\text { weight of pups at 0- } \\
24 \mathrm{~h} \text { after birth (g) }\end{array}$} \\
\hline & & & Total & Average in each litter & \\
\hline Control & 7 & 6 & 33 & $5.5 \pm 1.87$ & $1.86 \pm 0.33$ \\
\hline $0.2 \mathrm{nmol} / \mathrm{kg}$ QDs & 7 & 6 & 40 & $6.67 \pm 1.75$ & $1.84 \pm 0.31$ \\
\hline $2 \mathrm{nmol} / \mathrm{kg}$ QDs & 7 & 6 & 39 & $6.5 \pm 2.43$ & $1.92 \pm 0.27$ \\
\hline
\end{tabular}

B

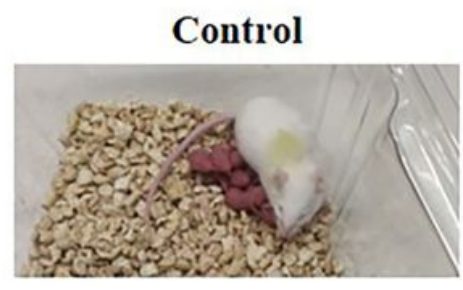

$0.2 \mathrm{nmol} / \mathrm{kg}$ QDs

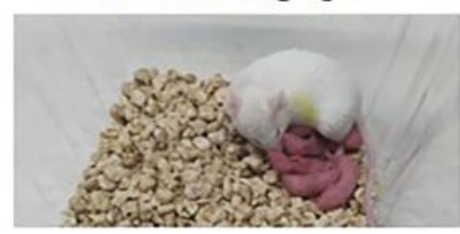

$2 \mathrm{nmol} / \mathrm{kg}$ QDs

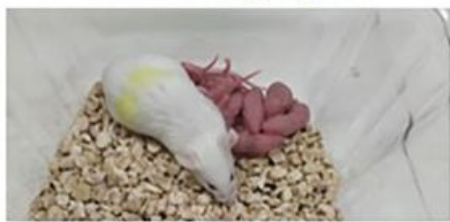

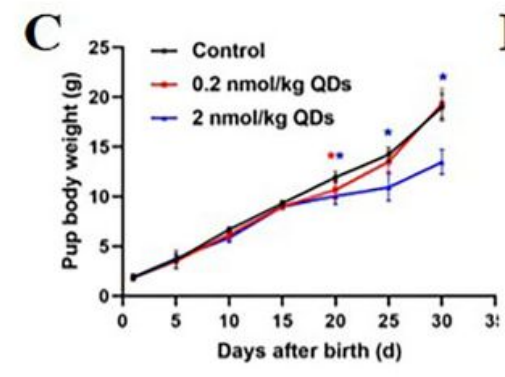
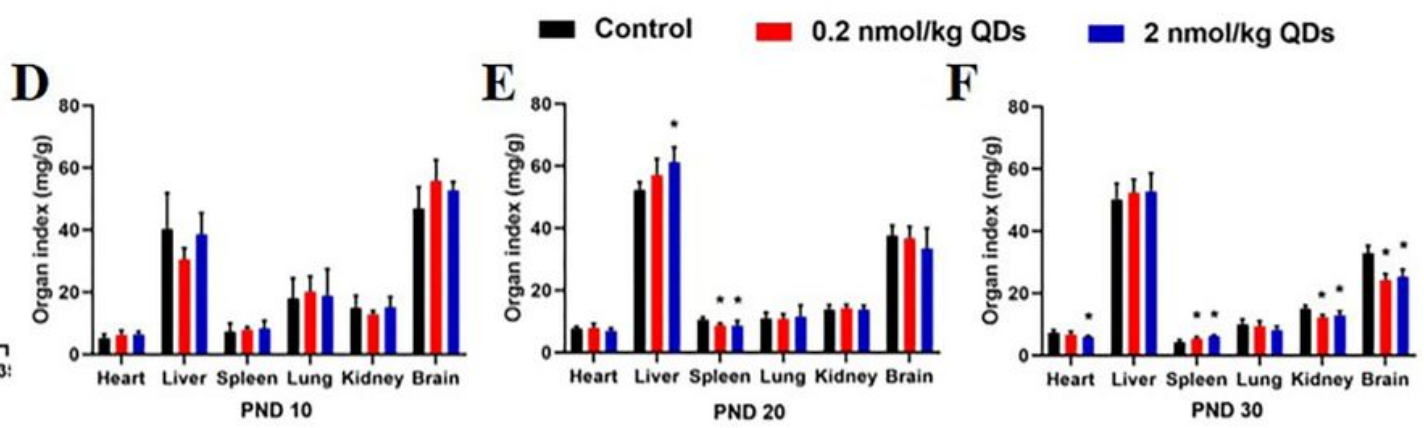

\section{Figure 8}

Reproductive ability and first litters of pups by male mice after intravenous injection of quantum dots or normal saline. (A) Fertility of male mice, number and body weight of their offspring. (B) Representative mouse parents and their litters of pups at $0-24 \mathrm{~h}$ after birth. (C) Changes in pup body weight within 30 days after birth. (D) Organ index of offspring mice on PND 10. (E) Organ index of offspring mice on PND 20. (F) Organ index of offspring mice on PND 30. (*Significantly different compared to control group at the same sampling time, $P<0.05$.) 

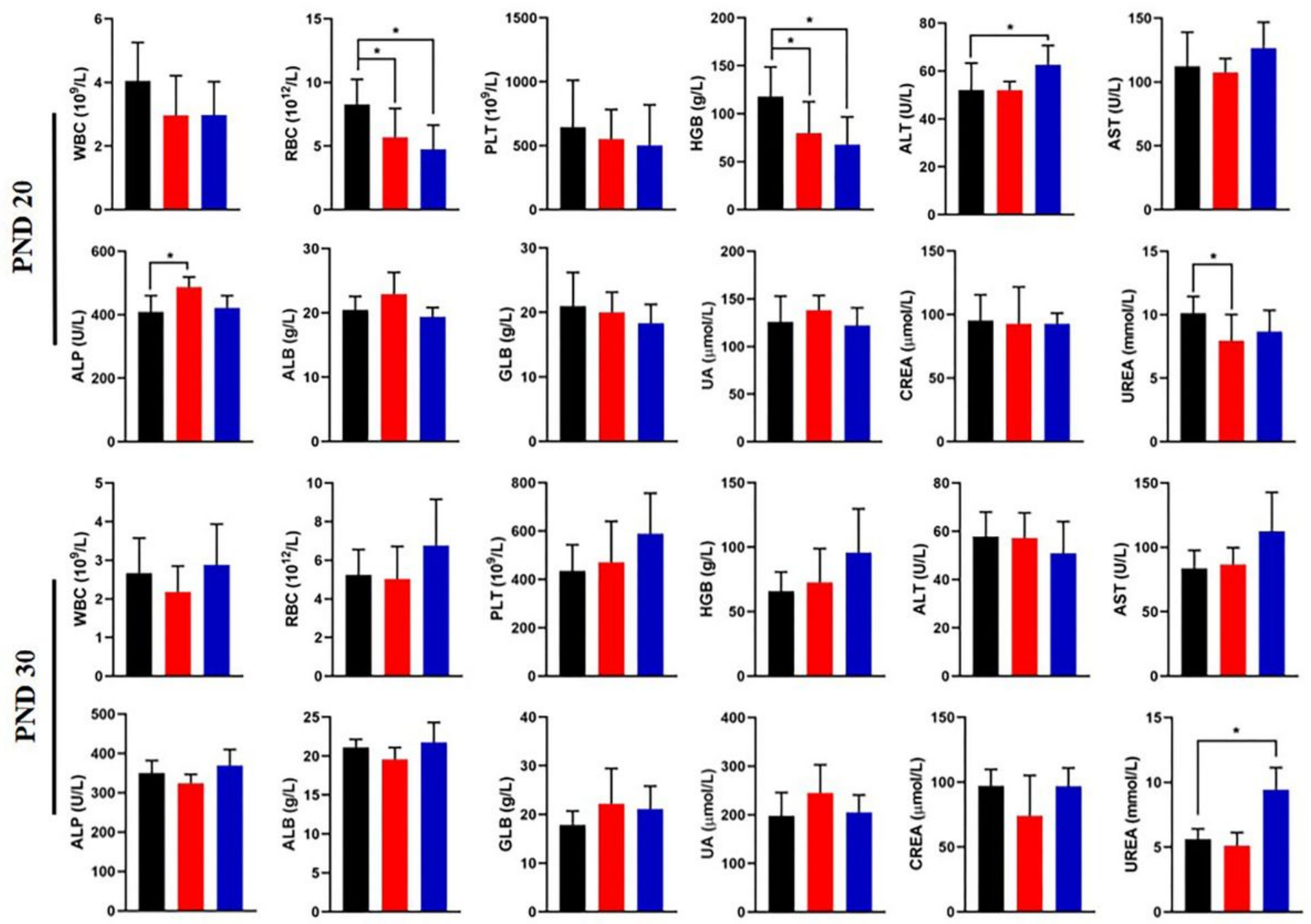

Figure 9

Hematology and serum biochemical data of offspring mice on PND 20 and 30. (*Significantly different compared to control group, $\mathrm{P}<0.05$.) 


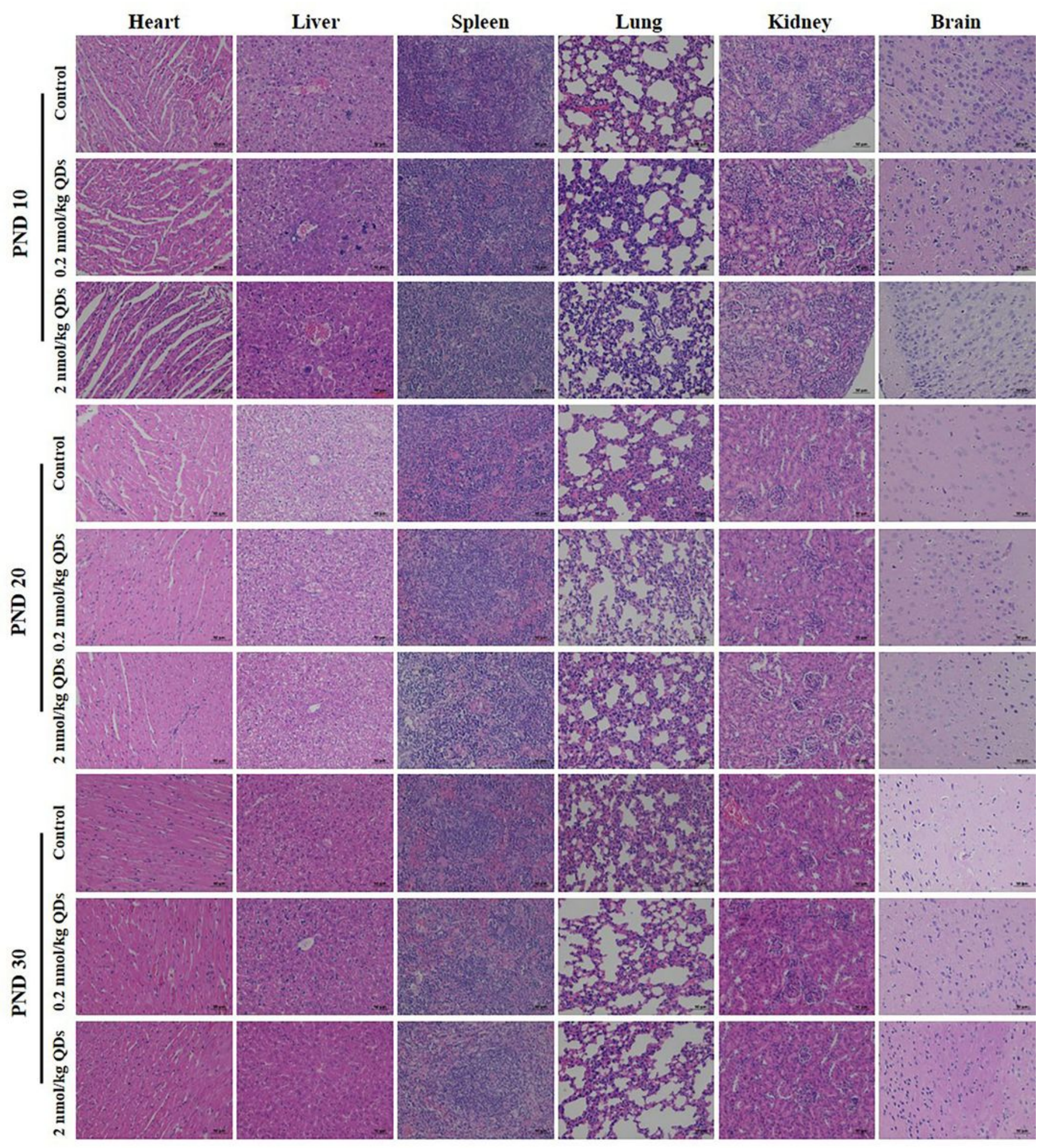

Figure 10

Representative H\&E staining images of main organ tissues of offspring mice on PND10, 20 and 30. (scale bar: $50 \mu \mathrm{m}$ ).

\section{Supplementary Files}


This is a list of supplementary files associated with this preprint. Click to download.

- supplementarymaterial.docx 